\title{
Bourdieu, Feminism and Female Physical Culture: Gender Reflexivity and the Habitus-Field Complex
}

\author{
Holly Thorpe \\ University of Waikato
}

Feminist theorizing in the sociology of sport and physical culture has progressed through ongoing and intense dialogue with an array of critical positions and voices in the social sciences (e.g., Judith Butler, R.W. Connell, Michel Foucault). Yet, somewhat surprisingly, the work of French sociologist Pierre Bourdieu-arguably one of modern sociology's "most important voices of social critique and theoretical innovation" (Krais, 2006, p. 120)—has gone largely unheard among critical sports scholars interested in gender (notable exceptions include Atencio, Beal \& Wilson, 2009; Brown, 2006; Kay \& Laberge, 2004; Laberge, 1995). In this paper I introduce recent feminist engagements with Bourdieu's original work to a critical sports sociology readership via a case study of snowboarding culture and female snowboarders. I begin by briefly examining the efficacy of three of Bourdieu's key concepts - capital, field and habitus-for explaining gender and embodiment in snowboarding culture. I then consider how the habitus-field complex can illustrate the "synchronous nature of constraint and freedom" (McNay, 2000 , p. 61) for women in contemporary physical culture.

La théorie féministe et la sociologie du sport et de la culture corporelle ont progressé par le biais d'un dialogue intense et continu entre des positions critiques et des voix provenant des sciences sociales (e.g. Butler, Connell, Foucault). Cependant, et de façon surprenante, les écrits du sociologue français Pierre Bourdieu, une des voix les plus importantes de la critique sociale et de l'innovation théorique selon Krais (2006), n'a généralement pas été entendue par ceux et celles qui ont fait des ouvrages critiques sur le sport et le genre (parmi les exceptions notables, on retrouve Atencio, Beal et Wilson, 2009; Brown, 2006; Kay et Laberge, 2004; Laberge, 1995). Dans cet article, je présente des écrits féministes récents qui touchent aux écrits originaux de Bourdieu par le biais d'une étude de cas de la culture de la planche à neige et des planchistes féminines. Je débute en expliquant brièvement l'efficacité de trois concepts bourdieusiens (le capital, le champ et l'habitus) pour discuter de genre et d'incarnation de la culture de la planche à neige. Enfin, je considère comment le complexe habitus-champ peut illustrer la nature synchronique de la contrainte et de la liberté chez les femmes dans la culture corporelle contemporaine. 
For many years, Pierre Bourdieu had little to say about women or gender with most of his writings framed preeminently in class. In the article "La Domination Masculine", however, Bourdieu (1990a) draws upon his ethnographic research into the Kabyle of North Africa to show how "masculine domination assumes a natural, self-evident status through its inscription in the objective structures of the social world", which is then embodied and reproduced in the habitus of individuals (McNay, 2000, p. 37). Although Kabyle is a peasant culture and his data were gathered during the 1960s, Bourdieu claims it exemplifies the ways in which gender hierarchies are maintained in modern industrial society.

The publication of "Masculine Domination" drew almost no reaction from feminist sociologists. It was only when the book version was released in 2001, that Bourdieu's analysis was noticed. However, it evoked strong criticisms from feminist scholars who argued that it presents an ahistorical, androcentric worldview and is "largely restricted to analyzing the structural constraints of masculine domination" (Fowler, 2003, p. 479). According to McLeod (2005), Bourdieu "writes defensively" in "Masculine Domination", and "appears somewhat oblivious to the diverse range of important feminist work that has historicized gender division. Moreover, his insights into gender reproduce standard binaries of masculine domination and female subordination as if these structures are unitary, coherent and unchanged by and in contemporary social life" (p. 53). Despite such criticisms, some feminist scholars, including Adkins (2003), Fowler (1997), Krais (2006), Lovell (2000), McCall (1992), McLeod (2005), McNay (1999, 2000), Moi (1991) and Skeggs (1997, 2004), recognized the potential in Bourdieu's social theory for "deepening and developing" (Walby, 2005, p. 376) feminist theorizing and set about deploying, rethinking and critically developing his conceptual schema.

In the remainder of this paper I introduce some of the arguments offered by these scholars and attempt to bring their work "to life" by offering a selection of insights from my ongoing analysis of women in snowboarding culture. ${ }^{1}$ First, I briefly examine the efficacy of three of Bourdieu's key concepts - capital, field and habitus - for explaining gender and embodiment in snowboarding culture. Second, I consider how the gender-habitus-field complex can illustrate the "synchronous nature of constraint and freedom" (McNay, 2000, p. 61) for women in contemporary physical cultures such as snowboarding. Ultimately, this discussion reveals that, while there needs to be much more sustained attention to the gendered dimensions of his conceptual schema, theoretical syntheses between feminism and Bourdieu offer new ways to productively reconceptualize the relationship between gender, power, structure, agency, reflexivity, culture and embodiment in sport and physical youth culture.

\section{Bourdieu and Feminism: Gendering Capital, Field and Habitus}

Throughout his work Bourdieu challenged many dualisms including theory and empirical work. In his own words, "research without theory is blind, and theory without research is empty" (Bourdieu \& Wacquant, 1992, p. 162). Thus, inspired by Bourdieu's unique research craft, empirical research on snowboarding culture forms the terra firma on which the following theoretical discussion is grounded. 
Drawing upon a type of methodology used extensively by Bourdieu and which he describes as "discursive montage" of "all sources" (Bourdieu \& Wacquant, 1992, p. 66), in this paper I engage his key concepts in conversation with my insider cultural knowledge of snowboarding, ${ }^{2}$ as well as numerous "ethnographic visits" conducted in six countries (Canada, France, Italy, New Zealand, Switzerland, the United States of America) between 2004 and 2009, more than 80 interviews with male and female snowboarders from various positions within the sport, culture and industry, and an extensive base of artifacts and sources collected over six years (see Thorpe, 2007a). Unfortunately, due to space limitations, only a selection of empirical insights can be offered here. However, the following discussion of the gendering of capital, field and habitus, and the subsequent examination of the gender-habitus-field complex offered in the second part of this paper, are both the result of an ongoing dialogue between theoretical knowledge and cultural knowledge, gained from previous and current cultural participation combined with multiple modes of data generation.

\section{Capital and Gender}

The concept of capital sits at the center of Bourdieu's (1985) construction of social space: "The structure of the social world is defined at every moment by the structure and distribution of the capital and profits characteristic of the different particular fields" (p. 734) and it is important to work out the correct hierarchy "of the different forms of capital" (p. 737). Capital refers to the different forms of power held by social agents. Bourdieu (1986) identifies various forms of capital (power), including economic (e.g., wealth), social (e.g., social connections), cultural (e.g., artistic taste), symbolic (e.g., prestige), linguistic (e.g., vocabulary and pronunciation), academic (e.g., tertiary qualifications), and corporeal (e.g., physical attractiveness). The power of an agent to accumulate various forms of capital, and to define those forms as legitimate, is proportionate to their position in the social space. According to Bourdieu, women are not typically capital-accumulating subjects. Rather, they are "capital bearing objects" whose value accrues to the primary groups to which they belong (e.g., her husband, the family) (Lovell, 2000; Skeggs, 2004). Feminist scholars, however, maintain that some women do pursue capital accumulating-strategies (see, e.g., Adkins, 2000; Lawler, 2000; Moi, 1991; Skeggs, 1997). Certainly, in snowboarding, core female boarders have accrued symbolic capital by showcasing their abilities and commitment.

Symbolic capital is another name for distinction. It is a "unique form of motivation-a resource, a reward" (Booth \& Loy, 1999, p. 4) closely tied up with the concepts of status, lifestyle, honor and prestige. Snowboarders assess symbolic capital in terms of style, commitment, abilities on challenging terrain, and difficulty and range of maneuvers. While some economic capital is necessary for participating in snowboarding, individuals cannot buy their way into the core of the culture. As New Zealand Snowboarder magazine put it, respect has "to be earned, usually with ... blood, sweat and tears" (Onset, 1995, p. 9). For many years, only the most committed males enjoyed access to symbolic capital. During the mid 1990s and 2000s, however, male boarders began to recognize and praise their female counterparts for displays of physical prowess, skill, aggression and courage. Recalling his first experience riding with Amy Howitt, professional boarder Todd Richards (2003) admitted his expectations were "pretty low" but he quickly conceded that she "hit 
big jumps and grabbed airs: rocket airs, mutes, methods" and most importantly "earned my respect" (p. 64). Increasingly, female boarders demonstrating legitimate physical prowess, skill, risk-taking, courage and commitment earn symbolic capital from male and female peers, the snowboarding media, and snowboarding companies (see Thorpe, 2005, 2008b).

Contemporary male and female snowboarders gain cultural status through exhibiting cultural commitment, physical prowess and risk-taking; some convert this symbolic capital into economic capital. The relationship between economic capital and cultural capital, however, is more complex than a direct exchange (Bourdieu, 1984). With bigger-than-life snowboarding personalities, professionals including Mark Frank Montoya, Shaun White, and Tara Dakides have been labeled cultural "superstars" by both the mainstream and snowboarding specific media (Is Snowboarding, 2002, para. 3). Bourdieu (1980) notes that to "'make one's name' means making one's mark, achieving recognition (in both senses) of one's difference from others ..." (p. 289). Professional snowboarders attempt to make their name through a combination of physical prowess and distinctive and marketable identities. Although physical prowess plays a key role in determining the symbolic capital possessed by a snowboarder, image is also crucial for converting this symbolic capital into economic capital. Top male snowboarders work hard to create distinctive hyper-masculine identities based on characteristics such as hedonistic and party lifestyles, gangster or punk identities, disregard for authority, heterosexual pursuits, and high jinks, or in the words of one participant, "shitty attitudes" and "booze [and] drugs" (Kelsey, personal communication [pc], September 2004; see Thorpe, 2007b). ${ }^{3}$ In an effort to convert symbolic capital into economic capital, some women construct a marketable snowboarding identity by drawing on their gender and femininity as a unique source of capital.

While symbolic, cultural and economic capital, are central to the structuring of Bourdieu's conception of social space, gender does not appear in his fundamental structuring principles. Bourdieu (1986) briefly acknowledges that "certain women derive occupational profit from their charm(s), and that beauty thus acquires a value on the labor market" (p. 245). Yet, he paid little attention to the relationship between gender and capital, and generally did not consider gender to be a form of capital. For Kay and Laberge (2002), Bourdieu's (1984) treatment of gender as a "secondary" constituent of social division contradicts claims elsewhere in his work that gender is a major principle of social stratification. Since the early 1990s, however, a number of feminist scholars have argued that women not only accumulate capital, but also possess their own feminine forms of capital (McCall, 1992; Huppatz, 2009; Lovell, 2000; Skeggs, 1997, 2004). According to Skeggs (1997), femininity is embodied, but it is also a learned competency and thus may operate as a form of capital. ${ }^{4}$ Femininity, as cultural capital, is "the discursive position available through gender relations that women are encouraged to inhabit and use. Its use will be informed by the network of social positions of class, gender, sexuality, region, age and race which ensure that it will be taken up (and resisted) in different ways" (Skeggs, 1997, p. 10). Also arguing for a positive engagement between Bourdieu's social theory and contemporary feminist theory, Lovell (2000) believes femininity as a form of cultural capital has increasing currency in the contemporary labor market. Building upon earlier feminist work, Huppatz (2009) recently distinguished between female capital — the gender advantage derived from 
being perceived to have a female (but not necessarily feminine) body_ - and feminine capital - the gender advantage derived from a disposition or skill set learned via socialization, or simply when members of a particular field recognize one's body as feminine - and described women capitalizing on their femaleness and femininity within particular occupations (e.g., paid caring work) to gain an income. It is important to note, however, that while the traditional feminine ideal continues to be encouraged and venerated in certain fields, notions of culturally valuable forms of femininity are constantly evolving and differ within and across fields; women wield femininity and femaleness as forms of capital in an array of innovative ways within different social fields (e.g., family, workforce, education, sport).

Certainly, abundant evidence demonstrates femininity as a potential form of cultural capital in the snowboarding field. For example, professional boarder Michele Taggart remembered female snowboarders in the late 1980s and early 1990s being "included [in media coverage] because of their cuteness and their beautiful hair" (cited in Howe, 1998, p. 64). Femininities, like masculinities, are assets in the snowboarding market, tradable for economic if not symbolic capital (Lovell, 2000). Committed Australian boarder Colin's response to the question, "what qualities does a female snowboarder need to become a professional" is enlightening here:

Determination and the ability to huck it with the boys. Looks help... However, Janna Meyen has got to the top of the game without relying on looks, by showing as much balls and determination, throwing down on the rails and slope-style course as any guy (pc, August 2004).

As this comment suggests, not all female snowboarders have access to femininity as a form of cultural capital. Moreover, within the contemporary snowboarding field, different groups of females privilege different forms of cultural investment. Whereas some female boarders acquire symbolic capital by demonstrating the traditionally-defined "masculine" traits of physical prowess, risk, and commitment (e.g., Janna Meyen), others overtly employ their femininity as a form of capital. ${ }^{5}$ While a great deal has been written about women's investments in their bodies as gendered and sexual bodies, I am particularly interested in young women's perceptions of the advantages (and problems) arising from ownership and promotion of feminine dispositions (see Thorpe, 2008a, 2008b).

The key issue here, however, is that in the male-defined symbolic structure of snowboarding, whatever form of capital female snowboarders possess in one respect, they tend to lose in others. For example, women choosing to privilege feminine capital are often written-off as "snow bunnies" uncommitted to the activity itself, while those who prioritize masculine capital and position themselves in opposition to the culturally valued discourse of stereotypical femininity, may experience ideological constraints (e.g., accusations of being "butch lesbians," field notes, 2005), and/or difficulty converting their symbolic capital into economic capital (e.g., sponsorship, media coverage). According to Bourdieu (2001), it is common for women to experience a "double bind" when attempting to access power; "if they behave like men, they risk losing the obligatory attributes of 'femininity' and call into question the natural right of men to the positions of power; if they behave like women, they appear incapable and unfit for the job" (p. 67). In the contemporary snowboarding field, however, some women appear to be overcoming this quandary by blurring the boundaries that divide the two. Professional snowboarder Tara 
Dakides proclaimed: "There's nothing wrong with being an athlete and a beautiful woman" (cited in Ulmer \& Straus, 2002, p. 17). Indeed, opportunities to transfer cultural capital into economic capital currently abound for a select few women who are able to accumulate both symbolic capital and feminine capital. According to EXPN.com, for example, Dakides combined a courageous and powerful riding style with a "rad SoCal style, gnarly fashion sense, lovely looks, and sense of humor" to become a snowboarding "diva" (Athlete Bios, 2002, p. 1, emphasis added). Clearly, some women are profiting from their investments in femininity in the snowboarding field. But, as a number of feminist scholars proclaim, feminine capital is a limited currency and "always operates within constraints" (Huppatz, 2009, p. 61).

It is not always easy, however, to "distinguish the difference between women's 'capital accumulating strategies' and the use of women by others as bearers of capital value" (Lovell, 2000, p. 25). While female snowboarders' investments in feminine capital may appear to be no more than another example of "women functioning to produce and reproduce social capital, creating ties between men which serve men's interests" (Lovell, 2000, p. 25) —and this may be one of the things it does-we should be cautious of overlooking or misinterpreting practices in which women are active agents with stakes in the field, and which are in large part self-interested (also see Thorpe, 2008a, 2008b). Perhaps Bourdieu had difficulty explaining women's capital preferences and accumulating abilities because, despite recognizing that women play a significant role in the processes of the gendered accumulation of capital, he rarely considered women as subjects with capital-accumulating strategies of their own. Drawing on the work of feminists scholars, however, we are encouraged to (re)consider the kinds of "investment strategies" women follow in particular circumstances. Indeed, in the second part of this paper I employ a feminist interpretation of Bourdieu's habitus-field nexus and, in so doing, recognize agency and reflexivity as central to understanding both young women's capital accumulating strategies, and how they negotiate their gendered habitus across different fields.

In sum, there needs to be much more sustained attention to the gendered dimensions of Bourdieu's notion of capital. Nonetheless, I believe it has the potential to offer a powerful resource for theorizing relations of power and privilege in contemporary society and physical cultures. Any questions regarding the "capitals" possessed by women, the composition of those capitals, their trajectory over time, and the control of their deployment, however, must be relative to historical and cultural contexts, and to the positions occupied by women within particular fields (Lovell, 2000; Skeggs, 1997, 2004).

\section{Field and Gender}

Field refers to a structured system of social positions occupied by either individuals or institutions engaged in the same activity. Fields are structured internally in terms of power relations. "In order for field to function", said Bourdieu (1993), "there have to be stakes and people prepared to play the game, endowed with the habitus that implies knowledge and recognition of the immanent laws of the field, the stakes, and so on" (p. 72). Within each field, individuals and groups (or classes $^{6}$ ) struggle to transform or preserve the configuration of power. The alpine snow field, for example, has traditionally consisted of two main groups: skiers and snowboarders. Although these groups share the same mountain space and comply 
with the same sets of rules (e.g., ski-resort etiquette), they each have their own institutions (e.g., associations, media, etc.), cultural rules, knowledge, practices and people. Over the past three decades, numerous power struggles developed between these two groups as they fought for territory and eminence (see Humphreys, 1996; Thorpe, 2004). Interestingly, in contrast to its united beginnings, the contemporary snowboarding field is highly fragmented. The rapid commercialization and popularization of snowboarding during the late 1990s and early 2000s fractured the field along geographical, commitment, equipment, ability, bodily disposition, style, and clothing lines, reinforcing the position of "established" groups and the marginal status of "outsider" groups (Thorpe, 2004). Importantly, gender is not the primary principle of division in the contemporary snowboarding field.

Although Bourdieu fails to consider the full implications of the concept of field in his work on gender, other theorists have claimed it has the potential to illuminate some of the "complexity and multilayeredness" of relations between the sexes in contemporary social life (Mottier, 2002, p. 355). Krais (2006), for example, argues that gender does not constitute a specific social field as it is sometimes assumed, but "enters into the 'game' of different social fields in ways specific to each field" (p. 128). Rather than a specific, autonomous field, gender is far better conceptualized as "part of a field" because, according to Adkins (2004), gender is "extraordinarily relational, with a chameleon-like flexibility, shifting in importance, value and effects from context to context or from field to field" (p. 6). Thus, while all fields contain and enforce a set of gender rules, some of these rules may be common to many other fields, whereas others may be specific to that field (Chambers, 2005). The field of snowboarding, for example, overlaps strongly with the surfing and skateboarding fields and they share similar cultural value systems, including some common gender rules (e.g., female surf, skate and snow boarders who demonstrate considerable physical prowess and cultural commitment typically have access to symbolic capital from their peers). However, these fields are not identical. Surfing, skateboarding and snowboarding also have distinctive histories, environments, geographies, identities and development patterns, as well as gender norms. The opportunities for a female boarder to convert symbolic capital into economic capital, for example, differ vastly between the snow, surf and skate fields, with female skateboarders typically having the least potential to do so within the hyper-masculine symbolic structure of skateboarding (see Atencio, Beal \& Wilson, 2009; Beal, 1996; Thorpe, 2006).

The contemporary snowboarding field is not ordered along gender lines. Rather, female boarders hold distinctive positions in each of the groups that make up the snowboarding field (e.g., professionals, core, weekend-warriors, and poseurs). The legitimate forms of femininity (and masculinity) differ between these groups. ${ }^{7}$ It is also important to note that gender relations are not produced in an invariant way across the snowboarding field. In Bourdieu's (1984) own words: "Sexual properties are as inseparable from class properties as the yellowness of a lemon is from its acidity: a class is defined in an essential respect by the place and value it gives to the two sexes and to their socially constituted dispositions" (p. 107). Put simply, class and gender are always intimately connected. ${ }^{8}$ This is why, in a highly fragmented snowboarding field, "there are as many ways of realizing femininity as there are classes and class fractions" (Bourdieu, 1984, p. 109). The interactions between men and women, and the most valued types of capital, vary between and within 
different classes or groups (e.g., core, weekend-warriors, novices and pro-hos) in the contemporary snowboarding field.

Core female boarders typically participate alongside their male peers. Hana, a top New Zealand snowboarder who rides, lives, works and travels with a group of "guys", negotiated space within the group by riding fast, keeping up with the boys, and dismissing "boy talk" that sexualizes and degrades "other" women (pc, April 2006). By demonstrating physical prowess and commitment, and ignoring symbolic violence (e.g., boy talk), Hana earned symbolic and cultural capital, and thus a place among her male peers. Yet she was conscious that other women are excluded from this group: "They treat me like one of the boys but I've seen them treat their girlfriends much worse" (pc, April 2006). Many core male snowboarders also enjoy sharing the snowboarding experience with their female friends. As one committed male boarder explained: "I love riding with girls with good skills. I think it's great when we can all ride together. There aren't many sports or pastimes where you can do that and have that much fun" (Nick, pc, April 2006). In contrast, the following narratives from a novice Canadian female snowboarder, highlight how some less-skilled women experience and explain their exclusion from groups of marginal male boarders or "weekend warriors":

I went snowboarding with [my boyfriend] and a couple of his buddies. This was one of the worst experiences for me. He went riding with his friends, and I rode alone for the day. I really don't think it was a gender thing, they are really nice guys and if I'd been a better snowboarder, I think I would have been allowed to ride with them. ... But they always expect me to not be as tough as them. If I get frostbite or are bummed out about something they are sensitive: "Are you too cold, honey?" "Do you want to go inside for a bit?" But they are much harder on each other. Them treating me that way, sort of babying me, I think, unconsciously gives them a sense of "ok, girls are still not at our level, this is still something I'm doing with the guys" (pc, November 2005; emphasis added).

Pro-hos (snowboarding's equivalent of groupies) have the least respect in the snowboarding field, as illustrated in the coarse words of the following male boarder: "Pro-hos just hang around trying to sleep with pro riders because they think it will make them cool-by-association and help them get into the good parties ... Most of them don't even snowboard. All a pro-ho is good for is a suck off" (Tom, pc, August 2004). The key point here is that female boarder's experience gender differently depending on their position within the snowboarding field.

In conclusion, this examination of the interaction of gender and social group distinction in the snowboarding field supports Bourdieu's claim that gender is a secondary principle of division. The embodied practices of snowboarders suggest that an individual's initial capital is gender-neutral, being fundamentally defined by their relative position in the structure based on their ability, commitment to the activity, and lifestyle. But, as illustrated by the "core" female boarders, "novices", "girlies", and "pro-hos", the legitimate forms of snowboarding femininity, preferred forms of capital (e.g., symbolic, gender), and gender relations, differ between groups. Of the various groups, it seems that "core" females have the most space to define and redefine cultural meanings pertaining to the female boarding body within the contemporary snowboarding field. Yet the rules structuring the snowboarding 
culture, and the gender relations within it, are not fixed but inherently contested by those within the field. Moreover, these struggles are not solely between men and women, but also between women (and between men) occupying different spaces within the field. Thus, in contrast to R.W. Connell's theory of social stratification (i.e., gender order) Bourdieu's conceptual schema moves beyond gender hierarchy. ${ }^{9}$ According to McNay (1999), the result of introducing such a notion of differentiation into an understanding of the social construction of gender identities is that "masculinity and femininity can be seen as imbricated in complex ways rather than as opposed and separate categories" (p. 112).

\section{Habitus and Gender}

Habitus refers to a set of acquired schemes of dispositions, perceptions and appreciations, including tastes, which orient our practices and give them meaning (Bourdieu, 1992). The habitus is both a "structured structure" - the effect of the actions of, and our interactions with, others - and a "structuring structure" - it suggests and constrains our future actions (Bourdieu, 1992, p. 53). In other words, habitus is both the "embodiment of our social location" (i.e., class, ethnicity, race, sexuality, gender, generation, and nationality) (Noble \& Watkins, 2003, p. 522) and "the structure of social relations that generate and give significance to individual likes (or taste) and dislikes with regard to practice and action" (Laberge, 1995, p. 136). Critically, the habitus is embodied, that is, "located within the body and affects every aspect of human embodiment" (Shilling, 1993, p. 129). Bourdieu generally uses the term hexis when referring to the embodied nature of the habitus. Hexis signifies "deportment, the manner and style in which actors 'carry themselves': stance, gait, gesture, etc" (Jenkins, 2002, p. 75). Bourdieu's concepts of habitus and hexis have the potential to help us to understand the ways in which embodied practices construct identity, difference and given social order in the snowboarding field.

The snowboarding habitus develops through practical engagement with snowboarding culture. The distinctive practices of a snowboarding habitus are imprinted and encoded in a socializing process that commences during early entry into the snowboarding field. It is during this socialization process that the "practical transmission" of boarding "knowledge" via instructors" and peers' comments, observation, and magazines and films, become embodied (Ford \& Brown, 2006, p. 123). Professional snowboarder Romain De Marchi identifies the habitus of core boarders: "it's kind of a fashionable thing" to snowboard these days but "the real snowboarders, have the passion and know the soul of snowboarding" (cited in Muzzey, 2003, p. 136, emphasis added). Todd Richards (2003) agrees: "Snowboarding is something you have to figure out. You have to earn it. You have to make it over different hurdles before it reveals its soul. And when that happens, its soul becomes part of you" (p. 281). The "soul of snowboarding" constitutes what Bourdieu (1971) calls "cultural unconscious" and it comes via "attitudes, aptitudes, knowledge, themes and problems, in short the whole system of categories of perception and thought" acquired by a systematic social apprenticeship (p. 182). Simply put, in snowboarding, the habitus or "cultural unconscious" derives from a systematic cultural apprenticeship, and the longer one spends immersed in snowboarding culture the more ingrained this habitus becomes. The socially constructed habitus of many core boarders is also generative, that is, it is a primary influence on their snowboarding practices. 
For example, choices of equipment, terrain ridden, and the style of riding, are made on the "basis of practically oriented dispositions that have already been inscribed in the body and subsequently take place without overtly direct conscious awareness of the principles that guide them" (Ford \& Brown, 2006, p. 126). Snowboarding culture is, therefore, a productive locus of a particular habitus which gives rise to, as Bourdieu (1971) says, "patterns of thought which organize reality by directing and organizing thinking about reality" (p. 194). Importantly, habitus not only helps reveal how the snowboarding culture is embodied, but also how taken-for-granted social inequalities are embedded in everyday practices.

While habitus is a complex and multilayered concept, Bourdieu is not always clear about the social or spatial boundaries of habitus formation-in other words, how we might identify the scale at which the habitus of a group or collective is defined. Bourdieu's unwillingness to specify the objective structures he believes generate a habitus can lead to problems in its operationalization (Reay, 1995). McRobbie (2009) admits finding analyses of the "intersections and flows between and across so many fields and so many habituses" methodologically overwhelming (p. 142). Despite recognizing the virtue in Bourdieu's schema for "bringing together" micrological analyses of particular fields with macro-sociological analyses of wider social, cultural and political fields, she warns of the tendency to "get lost in a proliferation of fields" (p. 141). In the case of snowboarding, for example, is it the local (e.g., geography, climate, peer group) or global (e.g., media) conditions that most strongly influence the formation of an individual's snowboarding habitus? On the other hand, perhaps Bourdieu's argument that theory should provide "thinking tools" to be deployed in empirical situations, rather than a clearly defined explanatory framework (Jenkins, 1992) ameliorates the confusion and leaves open a set of possibilities concerning the identification of habitus in a particular field. While the definition of the snowboarding group and field may be almost infinite, I focus on the 'collective' snowboarding field or what some cultural commentators refer to as the "global snowboarding culture" (Sherowski, 2004, p. 106) to provide an introductory set of observations. ${ }^{10}$

Another area requiring more sustained reflection is the intersection between habitus and gender. ${ }^{11}$ Throughout his work, Bourdieu took cognizance of the fact that men and women use and manage their bodies in very different ways in most cultures. Yet it wasn't until late in his career that he attempted to explain how this type of learning, which affects men's and women's perceptions of their bodies and selves, does not occur at the cognitive level but at the bodily level (Burkitt, 1999). In other words, Bourdieu was concerned with how gendered norms, and particularly gender inequality, becomes embodied. The concept of habitus is central here. Gendered habitus broadly refers to the "social construction of masculinity and femininity that shapes the body, defines how the body is perceived, forms the body's habits and possibilities for expression, and thus determines the individuals identity_via the body_as masculine or feminine" (Krais, 2006, p. 121). According to Bourdieu (1997), gender is an "absolutely fundamental dimension of the habitus that, like the sharps and clefs in music, modifies all the social qualities that are connected to the fundamental social factors" (translated by Krais, 2006, p. 128). Put slightly differently, the gender-specificity of habitus is among the fundamental elements of a person's identity primarily because it "touches the individual in an aspect of his/her self that is generally seen as 'pure nature': the body" (Krais, 2006, 
p. 121). Indeed, it is with this bodily reference that gender differentiation becomes "deeply and firmly" anchored in the habitus (Krais, 2006, p. 121).

Since a central element of Bourdieu's work is his argument that habitus develops in response to field, it seems logical to ask which field is responsible for the development of a gendered habitus (Chambers, 2005). For Bourdieu (1992), the habitus, which "at every moment, structures new experiences in accordance with the structures produced by past experiences" is "modified by new experiences... [to] bring about a unique integration" (p. 60). Early experiences, however, have particular weight because the habitus "tends to ensure its own constancy and its defense against change through the selection it makes within new information by rejecting information capable of calling into question its accumulated information" (Bourdieu, 1992, p. 60). He views the dispositions, which make up gendered habitus, as the products of opportunities and constraints framing the individual's earlier life experiences. They are "durably inculcated by the possibilities and impossibilities, freedoms and necessities, opportunities and prohibitions inscribed in the objective conditions" (Bourdieu, 1992, p. 54).

The confusion here, however, occurs when we try to understand how this gendered habitus, instilled from an early age, intersects with the snowboarding habitus, embodied later in life by many core female boarders via enculturation into the snowboarding field. As alluded to in the following comment, the weight of past experiences or, rather, the gendered habitus instilled from childhood, continues to influence the way some female snowboarders think about their bodies:

We are girls...we still have that feminine aspect. I think it's really hard to overcome that, and you feel like you still have to be a lady. But in order to ride this stuff, you need to have serious balls. When I can't do something, I say that it's 'cos I'm not a boy but, really, fuck that, there should be no difference between girls and boys, right? We are capable of doing anything we wanna do, right? But sometimes it's just so hard to get over that negative way of thinking... sometimes you just can't do it (Moriah, pc, November 2005).

Here, Moriah voices confusion in mediating the new social messages about the potential of the female body (e.g., "girls can do anything") and her deeply entrenched gendered habitus (e.g., "I can't do something...cos I'm not a boy"). But Moriah adds an interesting caveat:

The young ten-year-old girls aren't going to be thinking like this. They've grown up with way more role models and stuff. These are the girls that are gonna be fucken doing it, and we are going to be the old ladies that will be like... "Yeah, we wanted to do it but it was just so hard" (pc, November 2005).

As this comment implies, habitus is context specific. Women will inevitably experience snowboarding in diverse ways based on the gendered habitus instilled during childhood in different historical periods and in different social, cultural and political contexts.

A particular strength of habitus is that it introduces a temporal dimension to an understanding of the body that is "missing in many accounts of gender" (McNay, 1999, p. 102). However, while the "praxeological notion of time embedded in the 
concept of habitus" highlights the "uncertainties inherent in even the most routine act of reproduction", it also "underscores the entrenched nature of normative social identity" (McNay, 1999, p. 103). As Moriah's comments above suggest, gendered habitus comprises a "layer of embodied experience that is not immediately amenable to self-fashioning" (McNay, 1999, p. 103). The concept of habitus draws our attention to the ways in which gendered values and expectations are imprinted on our bodies, but there is little room for change, or resisting gender norms, in Bourdieu's original work. In Masculine Domination, he describes women "condemned" to participate in symbolic violence of gender and compelled to adhere to structures and agents of domination (p. 30). ${ }^{12}$ The common criticism of Bourdieu's work, that is its implications of determinism, seems particularly relevant in the context of his discussion of habitus and gender.

It is frequently argued that Bourdieu's conceptual schema reveals an "impoverished, two-dimensional model of individuals and agency" (Jenkins, 2002, p. 93). The emphasis on social reproduction in Bourdieu's work affects the degree to which people are able to exercise agency. Arguably, this leads him inexorably into deterministic explanations. In Bourdieu's (1985) own words:

The social world is, to a large extent, what the agents make of it, at each moment; but they have no chance of unmaking it and re-making it except on the basis of realistic knowledge of what it is and what they can do from the position they occupy within it (p. 728).

This is a social world "where behavior has its causes but actors are not allowed their reasons" (Jenkins, 2002, p. 97). The deterministic nature of Bourdieu's social theory troubles many (e.g., Jenkins, 1992, 2002; Shilling, 2004). McNay (1999), however, sees virtue in the generative nature of habitus, arguing that it helps explain the persistence of reasonably entrenched gender identities. For McNay (1999), the very value in Bourdieu's work is that it demonstrates the difficulty of change: it "provides a corrective to certain theories of reflexive transformation which overestimate the extent to which individuals living in post-traditional order are able to shape identity" (p. 113). Certainly, while some female snowboarders are able to negotiate space within the snowboarding field and accumulate capital (symbolic, gender and both), their gender identities remain limited and determined by a male valuation system (see Anderson, 1999; Thorpe, 2005). Olympic New Zealand snowboarder Pamela Bell, for example, complained of “unfair expectations of girls' abilities, as if there is only one scale of judgment - the boys' scale" (cited in Webster, 1996, p. 43). Professional American boarder Roberta Rodger also declared snowboarding "a male-dominated sport —on the slopes, in the magazines, and in the management of every snowboard company" (cited in Rodgers, 2001, para. 4). The notion of habitus illuminates the "entrenched dimensions" of embodied experiences and, in particular, male and female snowboarders' "deep-seated, often unconscious investments in conventional images of masculinity and femininity which cannot easily be reshaped" (McNay, 1999, p. 103).

It is important to bear in mind, however, that some female snowboarders (e.g., Pamela, Roberta) are critically aware of such gender inequalities and are creating new social, cultural and financial opportunities for themselves within the snowboarding field (see Thorpe 2005, 2007a, 2008a, 2008b). But, the reasons a female 
snowboarder gives for her embodied and reflexive practices would be of little concern to Bourdieu. For him, the actors' own explanations of their practices tend to be an illusion; the true explanation of behavior exists in the habitus. McCall (1992) argues that Bourdieu "stops short of realizing the potential of gendered dispositions because he considers female gender status imbued only with uncontested symbolic violence" (p. 845). ${ }^{13}$ Some female snowboarders actively resist the male bodily hexis and make attempts to redefine the female snowboarding body. But with Bourdieu's concept of habitus, it is difficult to understand the source of such impulses. Thus, a key question facing feminists is whether Bourdieu's work gives any chance for explaining agency and reflexive awareness. As a response to this question, the second part of this paper examines the potential of the habitus-field complex for explaining gender reflexivity in contemporary sport and physical culture.

\section{Habitus, Field and Gender Reflexivity}

While most criticisms of habitus invoke determinism, some of Bourdieu's texts provide more space for agency and reflexivity than others. In particular, in some of his later work, especially State Nobility, Bourdieu (1998) suggests that moments of disalignment and tension between habitus and field may give rise to increased reflexive awareness. For Bourdieu, habitus operates at an unconscious level unless individuals with a well-developed habitus find themselves moving across new, unfamiliar fields. It is in such moments that an individual's habitus may become "divided against itself, in constant negotiation with itself and its ambivalences" resulting in "a kind of duplication, to a double perception of the self" (Bourdieu, 1999, cited in Reay, 2004, p. 436). This becomes what Bourdieu (2003) has termed a habitus clivé, a "split habitus" (cited in Krais, 2006, p. 130). For Bourdieu, reflexive awareness arises from the "negotiation of discrepancies by individuals in their movement within and across fields of social action" (McNay, 1999, p. 110; see also Powell, 2008). Bourdieu was careful to emphasize, however, that despite a proliferation of fields and an increasingly mobile population, such disjunctions between habitus and field are not common occurrences. Chambers (2005) notes that "most people tend to remain within compatible fields most of the time", thus there is usually a fit between field and habitus (p. 340). In such circumstances, the habitus tends to be reinforced rather than challenged. Therefore, Bourdieu shows how reflexivity is not an inherently universal capacity of subjects, rather, it is a "piecemeal, discontinuous affair" (McNay, 1999, p. 110), uneven in its application, emerging only with its experience of dissonance.

Although Bourdieu acknowledges the "destabilizing and potentially subversive effects that might arise from movement across fields", he ignores what this might imply for an understanding of modern gender identity (McNay, 1999, p. 107). In Masculine Domination he fails to fully integrate the notion of habitus with his work on the concept of the field. This is problematic because, in contrast to traditional societies, such as the Kabyle, modern society is marked by the "complexity of its structures, criteria and social differentiations" and the experiences of individuals in general, and women in particular, are heterogeneous and contradictory, "encompassing not only practices of subordination to masculine domination, but also practices in which women assert independence and receive recognition for their work" (Krais, 
2006, p. 131). According to McNay (1999), while Bourdieu is "undoubtedly right to stress the ingrained nature of gender norms" his lack of a sustained consideration of gendered habitus in relation to the field means he "significantly underestimates the ambiguities and dissonances that exist in the way that men and women occupy masculine and feminine positions" in contemporary society (p. 107). In so doing, he is inattentive to the "internally complex nature of subjectivity" (McNay, 2000, p. 72), as well as the impact of particular social changes on how women "inhabit, experience, move across, change and are changed by new and emerging social fields, as well as by gender relations within existing fields" (Kenway \& McLeod, 2005, p. 535).

Despite such oversights, some feminist scholars have identified potential in the concepts of field and habitus for understanding how reflexive awareness might arise with regard to gender identity. In particular, McNay (1999) has drawn out these implications to show that gender reflexivity, or the questioning of conventional notions of femininity, does not arise from exposure to, and identification with, a greater array of alternative images of femininity, but rather from "tensions inherent in the concrete negotiation of increasing conflictual female roles" which occurs when women move between various social fields (e.g., family, work, sport) (p. 111; also see Adams, 2006; Hills, 2006; McNay, 2000). Thus, feminist syntheses of gender, habitus and the relational concept of field, yield "a framework in which to conceptualize the uneven and non-systematic ways in which subordination and autonomy are realized in women's lives" (McNay, 1999, p. 113) including their sport, physical culture and snowboarding experiences.

\section{Field Crossing, Gender Reflexivity and Female Physical Culture}

Upon entering the snowboarding field, some (not all) women experience a disjunction between habitus and field as they are (temporarily) distanced from constitutive structures (e.g., family, workforce, other sports fields). For some women, this movement across fields leads to gender reflexivity. For example, Amy Spence, a beginner snowboarder, describes entering the snowboarding field as helping her reflect upon everyday domestic and familial gender constraints:

I'm on chairlift \#8 at Mount Snow in Vermont, a borrowed snowboard dangling from my left foot, the bright April sun's warmth helping me temporarily forget my sore, wet body... For a moment, I forget my age, my gender, my responsibilities as a mother and wife. ... [With] my blonde hair stuffed in under a hat, my face hidden under Oakley's, my body disguised by my baggy coat and pants...I could be any age, any gender. But I'm not. Here I am, a 29 year-old-woman who, only after three days, is ready to trade in her world for the flight on the board. (cited in Carlson, 1999, p. 3)

Movement across the fields of work and snowboarding also encourages Marie, a Canadian novice snowboarder, to reflect upon differing feminine ideals and gendered norms in these two fields:

I wear mascara and heeled shoes everyday to work. But when we go to the mountain in the weekend I get to be less feminine and I really like that. I can, what I call, "get dirty," wear no makeup, maybe not shower in the morning, 
get sweaty, and hang-out with my friends. I'll have a burger and fries at lunch, which I wouldn't do when I'm off the mountain. When you put on a snowboard jacket and several layers, you can feel fun and cool and sexy, and no one can tell if you're ten pounds overweight...so there aren't as many body image worries as in my day-to-day city life (pc, November 2005).

When top New Zealand snowboarder Hayley Holt was asked why she quit competitive ballroom dancing and chose to focus on a snowboarding career, she replied, "snowboarding was more my thing, I didn't have to pretend to be a lady anymore" (cited in Catsburg, 2005, p. 110, emphasis added). Arguably, Holt's movement between the sports fields of ballroom dancing and snowboarding prompted her to critically reflect on gendered aspects of her habitus instilled from early (and prolonged) socialization into ballroom dancing culture.

Furthermore, as some female snowboarders move between overlapping but distinct groups within the field of snowboarding (e.g., competitive sport, industry), they become critically aware that, while "all fields embody gender rules, and some gender rules apply in all fields", gender norms are not identical across all fields or even groups within fields (Chambers, 2005, p. 333). For example, when pregnancy compelled professional snowboarder and 1998 Olympic halfpipe bronze medalist Shannon Dunn to take a step back from the field of competitive snowboarding it enabled her to look at women's snowboarding from a different perspective (Stravers, 2004). Observing significant gender inequalities in the media coverage of female boarders for the first time, Dunn vowed to initiate change and she set about organizing the "P-Jamma Party", a four day, all female, noncompetitive event with the aim of maximizing female exposure through editorial photos and $\mathrm{TV} /$ video coverage. Interestingly, some male participants also become aware of variations in gender norms and practices as they move across different fields, which in some cases may lead to increased critical reflexivity. For example, after more than a decade immersed in the skateboarding and surfing cultures, Ste'en learned to snowboard in the late 1980s and immediately observed differences in gender relations within the snow, skate and surf fields: "There were really no attitudes towards women snowboarding when I started ... especially compared to other sports like skateboarding and surfing where women are perceived in different ways (kind of), which can make it quite intimidating for women who are starting out" (pc, May 2003).

Arguably, as women (and some men) increasingly move across various fields (e.g., the home, family, workforce, different sport cultures, the ski resort), and positions within fields (e.g., novice, weekend-warrior, athlete, event organizer), they may experience conflicts between different concepts of order and ways of behaving that may generate "questions as to the 'naturalness' of established gender practices" (Krais, 2006, p. 131). Experiencing the tensions between different fields can, according to Adams (2006), "create dissonance and an awareness of 'objective' gender relations in these fields": the "lucidity of the excluded" can in turn generate resistance and negotiation (p. 518). Bourdieu makes a similar argument when not discussing gender: "It is difficult to control the first inclination of habitus, but reflexive analysis, which teaches that we are the ones who endow the situation with part of the potency it has over us, allows us to alter our perception of the situation and thereby our reaction to it" (Bourdieu \& Wacquant, 1992, p. 136). 
With only some women critically reflecting upon gendered dimensions of their habitus, and only a select few attempting to initiate changes in the sport, culture and industry of snowboarding, it is necessary to consider who is likely to do so. The ability to reflexively analyze gender norms in snowboarding culture tends to depend on the individual's gendered habitus instilled during childhood, their lived experiences and position in the snowboarding field, and the opportunities available for them to move across social fields (e.g., work, education, home, sport, leisure). For example, it appears that young "core" female snowboarders-whose work, accommodation, friendships and intimate relationships, and travel experiences, are typically organized around snowboarding-tend to do the least amount of field crossing, which may help explain why they often demonstrate limited critical reflection in relation to gender inequalities in the snowboarding field. But, as demonstrated in the Shannon Dunn example above, upon leaving the "core" group (whether this is due to the pursuit of professional or educational opportunities, injury, marriage, pregnancy, or any other reason) and entering "other" fields (e.g., work, sport, leisure, family), some women reflect differently on the gender and sexual politics of their experiences in the masculine snowboarding field; observing gender disparities, a select few become inspired to improve conditions for the next generation (see Thorpe, 2005, 2008a, 2008b). It is important to note, however, that mobility within and between fields, and in regard to gender styles, is a privileged position (Adkins, 2002). Perhaps it is worthwhile considering then whether the increased opportunities for young middle- and upper-class women-notably this is the background of most female snowboarders (see Thorpe, 2007a) - to move across multiple fields, and enter spheres that were previously closed to them (e.g., workplaces and sports traditionally-defined as masculine) has increased their potential for reflexivity. If this is the case, one way of encouraging further reflexivity and changes in gendered habitus may be, as Chambers (2005) suggests, to encourage more "interaction between fields, between communities or ways of life, so that individuals become aware of new options" (p. 340).

Of course, the presence of reflexivity does not automatically translate into identity transformation. As highlighted in Moriah's comments above, in some circumstances "our capacity for reflexive thought can leave us recognizing but unable to do anything about our lack of freedom" (Craib, 1992, p. 150; see also Adams, 2006; Brooks \& Wee, 2008). Even when women experience a disjunction between habitus and field leading to gender reflexivity, these alterations do not necessarily work to "undermine gender, or masculine domination" (Chambers, 2005, p. 343). As women enter into new fields certain aspects of gender relations may be destabilized, yet other aspects may be further entrenched (McNay, 1999). Indeed, as women enter male-dominated fields, many make adaptations and adopt strategies to "manage the masculine culture into which they are entering" (Chambers, 2005, p. 342). This also seems true of some women in snowboarding culture, particularly core female boarders who engage in prolonged periods of enculturation into, and sustained participation within, the snowboarding field, and thus have most fully embodied the (masculine) snowboarding habitus. Mel, for instance, a passionate New Zealand boarder who has worked successfully in the snowboarding industry for more than a decade and continues to hold a dominant position in the field as a competition judge, insists: Women in the snowboard- 
ing culture "have to have a very open mind and accept a lot of things that you may not agree with" (pc, October 2006). Clearly, the "cultural inculcation" of symbolic violence in the snowboarding field continues to be "exercised with the complicity" of (some) female boarders (McRobbie, 2009, p. 140; see also Krais, 1993; McNay, 1999, 2000).

The contemporary snowboarding field is a contradictory social context of ongoing sexism and greater opportunities for women (Thorpe, 2005). It would be a mistake, however, to assume that core female boarders passively embody the masculine snowboarding habitus during their participation within the field, and only begin to critically reflect on their gendered experiences upon exiting, or moving to a different position (e.g., weekend warrior) within, the field. Rather, core female snowboarders frequently encounter differences and problems within the field, which encourage them to engage in day-to-day negotiations of gender identity. In theorizing critical reflexivity and gender identity transformation then, we need to recognize that there is a continuum from relatively minor daily conflicts within fields, to more serious experiences of dissonance as individuals cross and enter new fields (Brooks \& Wee, 2008). In other words, we need a way of conceptualizing the habitus that "recognizes its potential for ambivalence, while acknowledging that this potential resides in relatively mundane conflicts as well as in more dramatic habitus-field mismatches" (Brooks \& Wee, 2008, p. 516; also see Mouzelis, 2007). Arguably, Bourdieu's (1991) notion of "regulated liberties"- small exercises of power that arise in the context of the existing social order, but which resignify it in some way-has the potential to help us capture some of the ambiguities, dissonances, and subtle negotiations of power experienced by young women within contemporary sport and physical cultural fields such as snowboarding.

Some core female boarders regularly engage in "regulated liberties"-small exercises of power that subtly resignify the female snowboarding body from within the field. For example, at the 1994 "Air and Style" big air snowboarding contest in Innsbruck (Austria), professional US snowboarders Tina Basich and Shannon Dunn openly defied the decision by contest organizers to exclude female participants. Dressed in pink snowboard outfits and pigtails, they hiked up the scaffolding and, with the large crowd rowdily cheering them, they proceeded to jump the gap on their snowboards (Basich, 2003; Howe, 1998). In so doing, Basich and Dunn actively challenged assumptions within the field regarding the legitimate use of the female boarding body (also see Thorpe, 2008a). The key point here is that these embodied practices "cannot be understood through binaries of domination and resistance, but rather involve more complex processes of investment and negotiation" (McNay, 2000, p. 58). While the various "regulated liberties" performed by female snowboarders (e.g., demonstrations of physical prowess and cultural commitment, defining their own styles and tastes, consciously ignoring "boy talk") may suggest gender instability within the snowboarding field, they do not guarantee reflexivity or gender identity transformation. In sum, a feminist turn to Bourdieu suggests that gender reflexivity in physical cultures such as snowboarding is "uneven and discontinuous", potentially arising as a result of mobility between social fields and, to a lesser extent, as a result of the requirements to reconcile the dissonant experiences that this invokes within fields (regulated liberties) (McNay, 1999, 2000; Kenway \& McLeod, 2005). 


\section{Gender Reflexivity and Change}

According to Bourdieu, an individual's conscious awareness does not by itself lead to fundamental social change. As Krais (2006) explains, Bourdieu vehemently argued against the "intellectualist illusion" — and in particular the position of Judith Butler - that simply performing individual acts of "deviant behavior" would be enough to overthrow dominating social structures (p. 131). For Bourdieu (2001), performativity and other regulated liberties fail to offer genuine opportunities for emancipation from structures of domination, for two main reasons. Firstly, regulated liberties are "performed by individuals", and so "lack the cohesive, collective character required for wide-ranging social change" and political mobilization necessary for effective resistance (Chambers, 2005, p. 339). Secondly, regulated liberties take place from "within the dominant context and corresponding habitus" and thus "do not really subvert those structures" (Chambers, 2005, p. 339). He claimed that practices often hailed as "resistant" may have an impact only on the relatively superficial "effective" relations of a field rather than its deeper structural relations (Bourdieu, 1992, cited in McNay, 1999, p. 105). Certainly, while some individual female boarders are critically aware of the gendered nature of their habitus, and are trying to create new social, cultural and financial opportunities for themselves within the sport, culture and industry of snowboarding, their efforts tend to be isolated to various dimensions of the snowboarding field.

Feminist scholars, including Chambers (2005) and Adkins (2003), add some interesting caveats to Bourdieu's thoughts on reflexivity and change. Chambers (2005), for example, argues that the strategies Bourdieu proposes for changeprincipally a disjunction between field and habitus, and the regulated liberties - are "not best suited to changes in gender systems" because "gender operates across fields" and "regulated liberties concerning gender are often reactionary" (p. 326). In her view, because gendered habitus tends to be reinforced in all fields it "cannot be significantly undermined by mobility across fields" (p. 343), and thus may be "even less susceptible to change than is the habitus more generally" (p. 323). Similarly, Adkins (2002) suggests that women might be regarded as "reflexivity losers" due to relative lack of mobility within and between fields, and the extent to which some forms of femininity have become naturalized across fields (p. 6). In a subsequent publication, Adkins (2003) suggests the presence of critical reflexivity may not be sufficient to warrant any discussion of identity transformation since it may be the case that, in the contemporary cultural moment, "reflexive practices are so habituated that they are part of the very norms, rules and expectation that govern gender in late modernity, even as they ostensibly appear to challenge these very notions" (p. 35). Making a similar point more broadly, Sweetman (2003) also argued that a flexible or reflexive habitus is increasingly common in late-, high-, or reflexive-modernity due to various economic, social and cultural shifts, which have lead to "a more or less permanent disruption of social positions, or a more or less constant disjunction between habitus and field" (p. 541). In this context, reflexivity "itself becomes habitual" such that certain contemporary individuals or groups "may easily and largely unquestioningly engage in reflexive projects of self (re)construction as a matter of course" (Sweetman, 2003, p. 542). Sweetman (2003) adds that, those displaying a reflexive habitus, "whilst at a potential advantage in certain respects, may also face considerable difficulties 'being them- 
selves"" (p. 528). ${ }^{14}$ While I prefer the slightly more sanguine interpretation of the gender-habitus-field complex offered by McNay (1999, 2000), the issues raised by Chambers (2005), Adkins (2002, 2003), and Sweetman (2003), may invigorate theoretical debates surrounding how best to understand and explain gender, identity, agency and social change in sport in the early twenty-first century. Clearly, there are many possible interpretations of Bourdieu's habitus-field nexus. My key argument here, however, is that some feminist extensions of his work are particularly useful because they have the potential to reveal both "change and continuity, intervention and repetition" (McLeod, 2005, p. 24) in gender identities and embodied practices in contemporary physical cultures such as snowboarding.

\section{Final Thoughts on Gendering Bourdieu}

In this paper I examined the recent feminist critiques of, and engagements with, Bourdieu's conceptual schema via a case study of snowboarding culture and female snowboarders. However, further research is needed that builds upon the theoretical aperture presented here and continues to explore the possibilities offered by Bourdieu's conceptual schema for deepening and developing theorizing of gender and the body and embodiment in sport and physical culture. Indeed, research that puts the gender-habitus-field complex "to work empirically" (Bourdieu \& Wacquant, 1992, p. 95, italics in original) has the potential to reveal more nuanced conceptualizations of gendered subjectivity, power relations, and transformations in contemporary physical cultures. Moreover, research that explores women's negotiations within and across differing social, cultural and sporting fields could enhance understanding of "their interpretations of powerful social and cultural discourses and practices" (Hills, 2006, p. 544), as well as their more subtle negotiations of gendered power relations within these fields. In this sense, Bourdieu's work appears to have much in common with Michel Foucault's theory and, therefore, a number of interesting commonalities in their work deserve comment (see also McNay, 2000).

As "theorists of constraint", Bourdieu and Foucault both spent much of their careers dissecting the relentless quest for normality across the social universe (McRobbie, 2009, p. 140). In their later work, however, both offered conceptions of the self that "attribute a degree of agency and self-determination to the individual without jettisoning [their] anti-essentialist view of the subject" (McNay, 1992, p. 62). Much like Bourdieu, Foucault $(1983,1988)$ rejects the notion of individuals "possessing an innate ability to...problematize their identities and to develop practices to change it" (Markula \& Pringle, 2006, p. 170; emphasis added). Critical thought (Bourdieu's "realistic knowledge") is also at the core of Foucault's understanding of technologies of self. According to Foucault (1983), the first step in the technologies of the self involves the individual gaining an ability to problematize their identity and the codes that govern them. For Foucault, it is only after such questioning that one can engage in ethical conduct or practices of freedom. Moreover, similar to Bourdieu's notion of "regulated liberties", Foucault does not believe that engaging in technologies of self necessarily transforms power relations or discourses. Rather, individuals attempt to minimize harmful modes of domination within relations of power. 
Reading Foucault's latter work, however, it is difficult to know where (some) individuals gain the impetus or ability to interrogate the limits of their own subjectivity. While Foucault offers fascinating insights into the various practices a critically reflexive subject may use to transform themselves within power relations (see Markula \& Pringle, 2006; Thorpe, 2008b), he is vague as to how individuals develop the capabilities to begin questioning the various effects of regimes of truth. Arguably, Bourdieu's habitus-field complex offers a more detailed account of the conditions of emergence for critical thought, which in some cases leads to gender reflexivity, or "regulated liberties" within existing power relations. McNay (1999) is particularly critical of what she describes as Foucault's "unresolved vacillation between determinism, on the one hand, and voluntarism on the other" or in other words between "docile bodies" and "reflexive" selves (p. 96). She argues that, by contrast, Bourdieu's concept of habitus as lived bodily practice opens up more theoretical space for "complex understandings of the interplay of social structures (fields) and individual agency, and elucidating the variability and creativity evident in reproductions of identity" (McNay, 1999, p. 101; see also Powell, 2008). Of course, all theories have strengths and shortcomings and, because they are a matter of perspective, are always open to debate. Conversations regarding the merits (and risks) of Bourdieu and Foucault's work for extending theorizing of gender, agency, and the body and embodiment in sport and physical culture, however, have the potential to shed light on some of the omissions in, and gaps between, these social theories, and highlight some areas where social theorizing of women in physical culture might be advanced.

Future research might also draw upon feminist texts, and use a range of sociological literature with other central foci (e.g., the body, physicality, identity, agency, reflexivity) that is modernizing Bourdieu's original work (e.g., Shilling, 2004; Sweetman, 2003), to fruitfully ask: What inter- and intra-field related ambiguities and dissonances do women in contemporary sport and physical cultures experience? How do they negotiate these tensions? What reflexive possibilities are available to them and what is the impact of the pre-reflexive aspects of their identities on their capacity to take up such opportunities within particular sports fields? How do women from different generations, and social, cultural, and political contexts, experience and negotiate tensions within, and across, various fields (Kenway \& McLeod, 2005)?

In sum, a virtue of feminist syntheses with Bourdieu's relational concepts of field and habitus is that they have the potential to highlight the "uneven and discontinuous" nature of changes in the gender identities of young women in contemporary society and physical culture per se (McNay, 1999, p. 109). Bourdieu's original work glossed over the "ambiguities and dissonances" existing in the occupation of "feminine subject positions" within and across particular fields, but an array of feminist scholars are "highlighting the importance of these subtle disidentifications in conceptualizing change and agency" (Hills, 2006, p. 553). Thus, gendered readings of capital, field and habitus have the potential to offer fresh insight into how the feminine subject is "synchronically produced as the object of regulatory norms by phallocentric symbolic systems and formed as a subject or agent who may resist these norms" (McNay, 1999, p. 105). In other words, gender identity in physical cultures, such as snowboarding, is "not a mechanistically determining structure but an open system of dispositions - regulated liberties - that are 'durable but not 
eternal"" (McNay, 1999, p. 105). While there needs to be much more sustained attention to the gendered dimensions of his conceptual schema, I believe a feminist interpretation of Pierre Bourdieu's conceptual schema can provide many fruitful opportunities for analyzing gender, power, structure, agency and reflexivity, in sport and physical culture.

\section{Notes}

1. While critical scholars of physical culture have readily employed Bourdieu's concepts to shed light on various aspects of the body and embodied practices, and social differentiation, in an array of sport and exercise fields (e.g., Crossley, 2004; Kay \& Laberge, 2002; Smith Maguire, 2002; Wacquant, 1995), his thoughts on gender have gone largely unnoticed. Among the exceptions (e.g., Kay \& Laberge, 2004; Laberge, 1995), Brown (2006) takes up Bourdieu's observation-somatization-naturalization thesis explaining the "everyday embodied enactments of gender relations in sport" (p.162) although he ignores feminist critiques which have been prolific and cogent. More recently (and while this paper was in its final stages of review), Atencio, Beal \& Wilson (2009) published an article that draws upon Bourdieu's concepts of capital, field, habitus and symbolic violence to offer an insightful analysis of gender and the skateboarding body. Somewhat surprisingly, however, they also overlook recent feminist debates.

2. During the 1990s and early 2000s I held many roles in the snowboarding field (i.e., novice, weekend-warrior, core boarder, semiprofessional athlete, snowboard instructor, event organizer, terrain-park employee, and journalist).

3. From hereafter, quotes from my personal communications (e.g., interviews) with participants will be abbreviated as 'pc'.

4. Of course, feminine capital may also be used by men, and masculine capital may also be used by women.

5. For similar observations in the skateboarding and windsurfing cultures, see Kelly, Pomerantz \& Currie (2005) and Wheaton \& Tomlinson (1998), respectively.

6. A class is a group of people whose "similar conditions of existence produce similar habituses and similar access to goods and power" (Jenkins, 2002, p. 140). While the majority of snowboarders are from the middle and upper classes, the snowboarding field constitutes a number of different groups with distinct tastes or preferences for cultural goods and consumption. Thus, employing Bourdieu's key concepts as "thinking tools" to be deployed in empirical situations, I substitute the term class with group due to the macro-connotations of the former. In so doing, Bourdieu's notions of field, class and taste have the potential to facilitate insights into snowboarding bodies as possessors of power, and the struggles between individuals and groups over the legitimate use and meaning of the body (Thorpe, 2004).

7. The influx of female participants during the late 1990s and 2000s, for example, saw individuals and groups increasingly clash over the meaning of their social identity, the legitimate use of the female boarding body, and the cultural value attributed to various forms of capital (i.e., gender, symbolic). In particular, ideological differences caused divisions between committed female boarders and recreational boarders and those whose participation is based on fashion, social status and heterosexual pursuits. Jenni indicates the hostility: "Girls who do things like stare at boys and sit in the pipe and on the sidelines of the park are just $\mathrm{f} * *$ king poseurs. They need to get a life and go have a sleepover in their thongs" (Girls And, 2003, no page or para.). Importantly, these comments allude not only to the divisions between groups of female boarders but also to a division between core and non-core boarders with the former demonstrating a commitment to the activity itself and thereby bearing an "authentic" cultural identity. This division is far more important than gender. 
8. Perhaps due to his concern with the French working classes, however, Bourdieu tended to gloss over certain inter-class differences (see Shilling, 2004), that would be pertinent to this discussion of intergroup gender relations within (and across) sports fields such as snowboarding, skateboarding and/or surfing.

9. For an interesting interpretation of Bourdieu's theory of fields in relation to the production and reproduction of multiple masculinities, see Coles (2009).

10. The interaction of local and global conditions in various social and physical spaces, and their influence on the development of the individual and collective snowboarding habitus, is significant and deserves further attention.

11. Due primarily to space limitations, the focus of this discussion is habitus and gender in the snowboarding field. I am, however, explicitly aware that gender is "only one part of an interconnected matrix of relations of power" (Birrell, 2000, p. 65). Moreover, as the embodiment of our social location, habitus includes gender and class, ethnicity, race, sexuality, generation, and nationality (Noble \& Watkins, 2003). Notably, a few feminist scholars have begun to critically extend and develop Bourdieu's work to offer intersectional analyses of gender, class and/or sexuality (see, for example, Allard, 2005; Fowler, 2003; McRobbie, 2004, 2009; Skeggs, 2004). Drawing upon such work and building upon the discussion offered here, I look forward to future research that engages habitus in more intersectional analyses of gender, class, race, ethnicity and sexuality in sport and physical cultures.

12. According to Bourdieu, symbolic violence is the imposition of systems of symbolism and meaning upon groups or classes in such a way that they are experienced as legitimate (Jenkins, 2002). This has been achieved through a process Bourdieu calls "misrecognition", whereby "power relations are perceived not for what they objectively are but in a form which renders them legitimate in the eyes of the beholder" (Jenkins, 1992, p. 104).

13. In this sense, there are some similarities between Bourdieu's concept of symbolic violence and R. W Connell's concept of hegemonic masculinity; both have been charged with employing a dualistic (oppressor-victim) model of power insufficient for explaining women's agency. Arguably, Bourdieu's notion of symbolic violence is more useful because it only functions in relation to Bourdieu's other concepts of field, capital, habitus and practice, and is grounded in the "real" and concerned primarily with the particular.

14. Interestingly, Sweetman (2003) also suggests that the adoption of particular lifestyles, "whilst dependent initially upon reflexive engagement with the various options that are available, may also reflect an attempt to evade demands for an ongoing reflexivity and to fix, or 'anchor' the self in what can be regarded as a modernist response to the contemporary social terrain" (p. 543). Arguably, Sweetman's (2003) work on habitus and reflexivity in the early twenty-first century has the potential to shed new light on ongoing conversations regarding sport and physical youth cultures and identity construction.

\section{Acknowledgments}

I would like to thank Douglas Booth, Richard Pringle, Robert Rinehart and the anonymous reviewers, for their helpful comments and suggestions in developing this paper. Special thanks to Pirkko Markula for her perceptive editorial skills.

\section{References}

Adams, M. (2006). Hybridizing habitus and reflexivity: Towards an understanding of contemporary identity? Sociology, 40(3), 511-528.

Adkins, L. (2000). Objects of innovation: Post-occupational reflexivity and re-traditionalizations of gender. In S. Ahmed, J. Kilby, M. McNeil \& B. Skeggs (Eds.), Transformations: Thinking through feminism. London: Routledge. 
Adkins, L. (2002). Revisions: Gender and sexuality in late modernity. Buckingham: Open University Press.

Adkins, L. (2003). Reflexivity: Freedom or habit of gender?'. Theory, Culture \& Society, 20(6), 21-42.

Adkins, L. (2004). Introduction: Feminism, Bourdieu and after. In L. Adkins \& B. Skeggs (Eds.), Feminism after Bourdieu (pp. 3-18). Oxford: Blackwell.

Allard, A. (2005). Capitalizing on Bourdieu: How useful are concepts of "social capital" and "social field" for researching "marginalized" young women? Theory and Research in Education, 3(1), 63-79.

Anderson, K. (1999). Snowboarding: The construction of gender in an emerging sport. Journal of Sport and Social Issues, 23(1), 55-79.

Atencio, M., Beal, B., \& Wilson, C. (2009). The distinction of risk: Urban skateboarding, street habitus and the construction of hierarchical gender relations. Qualitative Research in Sport and Exercise, 1(1), 3-20.

Athlete Bios. (2002). Retrieved March 10, 2003, from http://expn.go.com/athletes/bios/ DAKIDES_TARA.html

Basich, T. with Gasperini, K. (2003). Pretty good for a girl: The autobiography of a snowboarding pioneer. New York: Harper Collins.

Beal, B. (1996). Alternative masculinity and its effects on gender relations in the subculture of skateboarding. Journal of Sport Behavior, 19, 204-221.

Birrell, S. (2000). Feminist theories for sport. In J. Coakley \& E. Dunning (Eds.), Handbook of sports studies (pp. 61-76). London: Sage Publications.

Booth, D., \& Loy, J. (1999). Sport, status, and style. Sport History Review, 30, 1-26.

Bourdieu, P. (1971). Intellectual Field and Creative Project. In M.F.D. Young (Ed.), Knowledge and control: New directions in the sociology of education (pp. 161-188). London: Collier-Macmillan.

Bourdieu, P. (1978). Sport and social class. Social Sciences Information. Information Sur les Sciences Sociales, 17(6), 819-840.

Bourdieu, P. (1980). The production of belief: contribution to an economy of symbolic goods. Media, Culture \& Society, 2, 261-293.

Bourdieu, P. (1984). Distinction: A social critique of the judgement of taste. London: Routledge.

Bourdieu, P. (1985). The social space and the genesis of groups. Theory and Society, 14, 723-744.

Bourdieu, P. (1986). The forms of capital. In J.G. Richardson (Ed.), Handbook of theory and research sociology of education (pp. 241-258). New York: Greenwood Press.

Bourdieu, P. (1990a). La Domination Masculine. Actes de la Recherche en Sciences Sociales, 84(Sept), 2-31.

Bourdieu, P. (1990b). In other words. Cambridge: Polity Press.

Bourdieu, P. (1991). Language and symbolic power. Cambridge: Polity Press.

Bourdieu, P. (1992). The logic of practice (Nice, R. (trans.)). Cambridge: Polity Press.

Bourdieu, P. (1993). The field of cultural production. Cambridge: Polity Press.

Bourdieu, P. (1998). State nobility. Cambridge: Polity Press.

Bourdieu, P. (2001). Masculine domination. Cambridge: Polity Press.

Bourdieu, P., \& Wacquant, L.J.D. (1992). The purpose of reflexive sociology. In Bourdieu \& Wacquant (Eds.), An invitation to reflexive sociology (pp. 61-215). Cambridge: Polity Press.

Brooks, A., \& Wee, L. (2008). Reflexivity and the transformation of gender identity: Reviewing the potential for change in a cosmopolitan city. Sociology, 42(3), 503-521.

Brown, D. (2006). Pierre Bourdieu's "Masculine Domination" thesis and the gendered body in sport and physical culture. Sociology of Sport Journal, 23(2), 162-188.

Burkitt, I. (1999). Bodies of thought: Embodiment, identity and modernity. London: Sage. Butler, J. (1997). Excitable speech: A politics of the performance. London: Routledge. 
Carlson, J. (1999). Snowboarding: A Ragged Mountain Press woman's guide. Camden: Ragged Mountain Press.

Catsburg, M. (2005). Sibling rivalry? Manual: New Zealand Skate and Snow Culture, 18, $110-116$.

Chambers, C. (2005). Masculine Domination, radical feminism and change. Feminist Theory, 6(3), 325-346.

Coles, T. (2009). Negotiating the field of masculinity: The production and reproduction of multiple dominant masculinities. Men and Masculinities, 12(1), 30-44.

Connell, R.W. (1987). Gender and power: Society, the person and sexual politics. Cambridge: Polity Press.

Craib, I. (1992). Anthony Giddens. London: Routledge.

Crossley, N. (2004). The circuit trainers' habitus: Reflexive body techniques and the sociality of the workout. Body \& Society, 10(1), 37-69.

Ford, N., \& Brown, D. (2006). Surfing and social theory. London: Routledge.

Foucault, M. (1983). The subject and power. In H. L. Dreyfus \& P. Rabinow (Eds.), Michel Foucault: Beyond structuralism and hermeneutics ( $2^{\text {nd }}$ Edition) (pp. 208-226). Chicago: University of Chicago Press.

Foucault, M. (1988). Technologies of the self. In L. H. Martin, H. Gutman, \& P. H. Hutton (Eds.), Technologies of the self: A seminar with Michel Foucault (pp. 16-49). Amherst, MA: University of Massachusetts Press.

Fowler, B. (2003). Reading Pierre Bourdieu's Masculine Domination: Notes towards an intersectional analysis of gender, culture and class. Cultural Studies, 17(3-4), 468-494.

Fowler, B. (1997). Pierre Bourdieu and cultural theory: Critical investigations. London: Sage

Girls and snowboarding. (2003, March 28). Boardpass.com. Retrieved January 19, 2004, from http://www.boardpass.com/search/snownews/replies. asp?IDCODE $=829$ andMainCode $=703$

Hills, L. (2006). Playing the field(s): An exploration of change, conformity and conflict in girls' understandings of gendered physicality in physical education. Gender and Education, 18(5), 539-556.

Howe, S. (1998). (SICK) A cultural history of snowboarding. New York: St. Martins Griffin.

Humphreys, D. (1996). Snowboarders: Bodies out of control and in conflict. Sporting Traditions, 13(1), 3-23.

Huppatz, K. (2009). Reworking Bourdieu's "capital": Feminine and female capitals in the field of paid caring work. Sociology, 43(1), 45-66.

Is snowboarding a religion? (2002, July). Retrieved June 7, 2004, from http://www.boardtheworld.com/magazine/editorial.php?month=2002-07-01

Jenkins, R. (1992). Pierre Bourdieu (1st ed.). London: Routledge.

Jenkins, R. (2002). Pierre Bourdieu (revised edition). London: Routledge.

Kay, J., \& Laberge, S. (2002). The "new" corporate habitus in adventure racing. International Review for the Sociology of Sport, 37(1), 17-36.

Kay, J., \& Laberge, S. (2004). 'Mandatory equipment': Women in adventure racing. In B. Wheaton (Ed.), Understanding lifestyle sports: Consumption, identity and difference (pp. 154-174). London, New York: Routledge.

Kelly, D., Pomerantz, S., \& Currie, D. (2005). Skater girlhood and emphasized femininity: "You can't land an olly properly in heels". Gender and Education, 17(3), 229-248.

Kenway, J., \& McLeod, J. (2004). Bourdieu's reflexive sociology and "spaces of points of view": Whose reflexivity, which perspective? British Journal of Sociology of Education, 25(4), 525-544.

Krais, B. (1993). Gender and symbolic violence: Female oppression in the light of Pierre Bourdieu's theory of social practice. In C. Calhohn, E. LiPuma, \& M. Postone (Eds.), Bourdieu: Critical perspectives (pp. 156-177). Cambridge: Polity Press.

Krais, B. (2006). Gender, sociological theory and Bourdieu's sociology of practice. Theory, Culture \& Society, 23(6), 119-134. 
Laberge, S. (1995). Toward an interpretation of gender into Bourdieu's concept of cultural capital. Sociology of Sport Journal, 12, 131-146.

Lawler, S. (2000). Mothering the self: Mothers, daughters, subjects. London: Routledge.

Lovell, T. (2000). Thinking feminism with and against Bourdieu. Feminist Theory, 1(1), $11-32$.

Markula, P. \& Pringle, R. (2006). Foucault, sport and exercise: Power, knowledge and transforming the self. London: Routledge.

McCall, L. (1992). Does gender fit? Bourdieu, feminism, and conceptions of social order. Theory and Society, 21, 837-867.

McLeod, J. (2005). Feminists rereading Bourdieu: Old debates and new questions about gender habitus and gender change. Theory and Research in Education, 3(1), 11-30.

McNay, L. (1992). Foucault and feminism: Power, gender and the self. Cambridge: Polity.

McNay, L. (1999). Gender, habitus and the field: Pierre Bourdieu and the limits of reflexivity. Theory, Culture \& Society, 16(1), 95-117.

McNay, L. (2000). Gender and agency: Reconfiguring the subject in feminist and social theory. Cambridge: Polity.

McRobbie, A. (2004). Notes on "what not to wear" and post-feminist symbolic violence. In L. Adkins \& B. Skeggs (Eds.), Feminism after Bourdieu (pp. 99-109). Oxford: Blackwell.

McRobbie, A. (2009). The aftermath of feminism: Gender, culture and social change. Los Angeles: Sage.

Moi, T. (1991). Appropriating Bourdieu: Feminist theory and Pierre Bourdieu's sociology of culture. New Literary History, 22, 1017-1049.

Mottier, V. (2002). Masculine domination: Gender and power in Bourdieu's writings. Feminist Theory, 3(3), 345-359.

Mouzelis, N. (2007). Habitus and reflexivity: Restructuring Bourdieu's theory of practice. Sociological Research Online, 12, 12(6) from http://www.socresonline.org.uk retrieved May 5, 2008.

Muzzey, J. (2003, April). Interview: Romain De Marchi. Transworld Snowboarding, 126-139.

Noble, G., \& Watkins, M. (2003). So, how did Bourdieu learn to play tennis? Habitus, consciousness and habituation. Cultural Studies, 17 (3/4), 520-538.

Onset: Respect. (1995, May/June). New Zealand Snowboarder, 9.

Powell, A. (2008). Amor fati? Gender habitus and young people's negotiation of (hetero) sexual consent. Journal of Sociology, 44(2), 167-184.

Reay, D. (1995). 'They employ cleaners to do that': Habitus in the primary classroom. British Journal of Sociology of Education, 16(3), 353-371.

Reay, D. (2004). "It's all becoming habitus": Beyond the habitual use of habitus in educational research. British Journal of Sociology of Education, 25(4), 431-444.

Richards, T. with Blehm, E. (2003). P3: Pipes, parks, and powder. New York: Harper Collins.

Rodgers, A. (2001, December). Carving out a niche. Retrieved from http://www.fastcompany. com/articles/2001/12/chorus.html

Sherowski, J. (2004, April). Notes from down-under. Transworld Snowboarding, 104-117.

Shilling, C. (1993). The body and social theory. London: Sage.

Shilling, C. (2004). Physical capital and situated action: A new direction for corporeal sociology. British Journal of Sociology of Education, 25(4), 473-487.

Skeggs, B. (1997). Formations of class and gender. London: Sage.

Skeggs, B. (2004). Context and background: Pierre Bourdieu's analysis of class, gender and sexuality. In L. Adkins \& B. Skeggs (Eds.), Feminism after Bourdieu (pp. 19-34). Oxford: Blackwell.

Smith Maguire, J. (2002). Body lessons: Fitness publishing and the cultural production of the fitness consumer. International Review for the Sociology of Sport, 37(3-4), 449-464.

Stravers, K. (2004, December). Ladies first. SG Surf, Snow, Skate Girl, 58-71.

Sweetman, P. (2003). Twenty-first century dis-ease? Habitual reflexivity or the reflexive habitus. The Sociological Review, 51(4), 528-548. 
Thorpe, H. (2004). Embodied boarders: Snowboarding, status and style. Waikato Journal of Education, 10, 181-201.

Thorpe, H. (2005). Jibbing the gender order: Females in the snowboarding culture. Sport in Society, 8(1), 76-100.

Thorpe, H. (2006). Beyond "decorative sociology": Contextualizing female surf, skate and snow boarding. Sociology of Sport Journal, 23(3), 205-228.

Thorpe, H. (2007a). Boarders, babes and bad-asses: Theories of a female physical youth culture. Unpublished $\mathrm{PhD}$, University of Waikato.

Thorpe, H. (2007b). Snowboarding. In D. Booth \& Thorpe (Eds.), Berkshire Encyclopedia of Extreme Sport (pp. 286-294). Berkshire, Great Barrington.

Thorpe, H. (2008a). Feminism for a new generation: A case study of women in snowboarding culture. In S. Thompson, C. Obel, \& T. Bruce (Eds.), Outstanding: Research about women and sport in New Zealand (pp. 7-30). Waikato: Wilf Malcolm Institute of Educational Research.

Thorpe, H. (2008b). Foucault, technologies of self, and the media: Discourses of femininity in snowboarding culture. Journal of Sport and Social Issues, 32(2), 199-229.

Ulmer, K., \& Straus, A. (2002). Action figures: the girls of extreme sports. Retrieved May 10, 2004, from http://www.maximonline.com/sports/girls_of_extreme_sports/dakides.html

Wacquant, L.J.D. (1995). Pugs at work: Bodily capital and bodily labor among professional boxers. Body \& Society, 1(1), 65-93.

Walby, S. (2005). The sociology of gender relations. In C. Calhoun, C. Rojek, \& B. Turner (Eds.), The Sage handbook of sociology (pp. 367-380). London: Sage.

Webster, S. (1996, August). Pamela Bell interview, New Zealand Snowboarder, 43.

Wheaton, B., \& Tomlinson, A. (1998). The changing gender order in sport? The case of windsurfing subcultures. Journal of Sport and Social Issues, 22(3), 252-274. 